\title{
Fatigue Loads Mitigation on Horizontal Axis Wind Turbines Using Aerodynamic Devices. A Survey
}

\author{
Patrick I. Muiruri" and Oboetswe s. Motsamai
}

\begin{abstract}
${ }^{1}$ Department of Mechanical Engineering, Faculty of Engineering and Technology, University of Botswana (UB), Pvt Bag 0061,
\end{abstract} Gaborone, Botswana

Received 27 April 2017; Accepted 15 September 2017

\begin{abstract}
The paper presents overview of source loads and aerodynamic techniques that are feasible for fatigue load reduction on large horizontal axis wind turbines. The article highlights the effects of increasing wind turbine rotor diameter on fatigue load, and feasible aerodynamic techniques that can be employed to reduce fatigue load. Increased in fatigue load is critical as current and future horizontal wind turbines are designed of large rotor blades. Increase in size of wind turbines has been elicited by highly demand for clean energy nowadays as well as need to decrease the cost of energy per kilo watt. As the rotor diameter increases in size, so do effects of air loads acting on the blades. The pitch control systems installed with a purpose of controlling such effects are approaching their capability limits. They are unable to dump sudden, high varying air loads associated with fluctuating wind speed on time. As these effects occur repeatedly during operation of wind turbines, they can cause premature failure or permanent damage of major components due to fatigue load accumulation. In overall, the service life of wind turbine can drastically reduce or high operational and maintenance costs are likely to rise up due to frequent downfalls of unplanned maintenance schedules. Therefore, alternative methods rather than pitch control are reviewed that can improve wind turbines efficiency. The paper concludes by analyzing possible opportunities in future.
\end{abstract}

Keywords: Aerodynamic techniques, Fatigue, Pitch control, Aerodynamic devices.

\section{Introduction}

Climate change has been recognized as a global challenge to environment worldwide and measures are ongoing to curb it. Accumulation of greenhouse gases from burning of fossil fuels in power generation and transport industries is a major cause towards global warming. As a result, the demand for clean and sustainable renewable energy rises sharply globally. In search for this energy, wind energy emerged to be placed as priority source among other renewable resources [1, 2]. It is considered as the fastest growing renewable energy with annual growth rate ranging from $30 \%$ to $34 \%$, despite occurring irregularly [3-5]. Wind energy is affordable, environmental friendly and free available source. It is believed that fossil fuel reserves are time bound. Most countries are, therefore, investing in wind energy while other assessing availability of utilizing it to circumvent risk that can be caused by rise of fuel market prices and lack of fuel supply due to war and political instability in producing fuel countries. Aforementioned facts make wind energy enjoy first priority in search for clean energy for domestic and industrial use. Fig.1, is evidence that wind energy is increasing in capacity in the recent decade. New emerging areas in Africa, Asian and Latin America with potential of producing wind energy are reported in renewable 2015 global status report [6]. However, to enhance wind energy competitiveness as compared to fossil fuels, the cost of

*E-mail address: pmuiruri@jkuat.ac.ke

ISSN: $1791-2377$ @ 2017 Eastern Macedonia and Thrace Institute of Technology. All rights reserved. doi:10.25103/|iestr.105.18 energy per kilo watt (COE) needs to be lowered further [7]. The debate on costs of energy reduction is based on three independent variables as shown in Eq. (1) [7].

$$
C O E=\frac{\text { Capital Cost }+ \text { Operation \& Maintenance costs }}{\text { Lifetimeenergy generation }}
$$

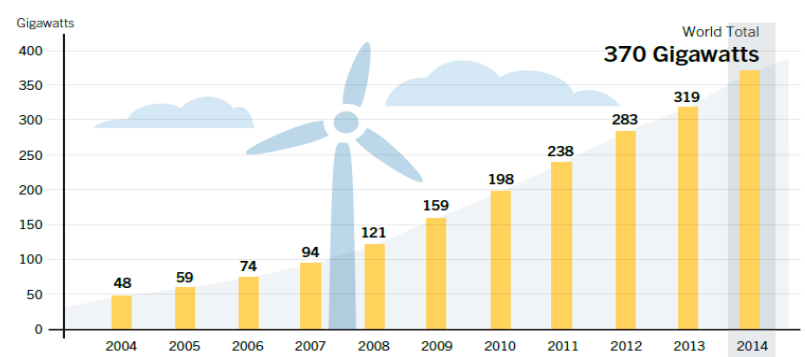

Fig.1. Approximated amount of total wind energy produced globally in decade at 2014 [6].

From Eq. (1) the COE can be lowered by either decreasing capital costs, operation and maintenance (O\&M) or both. This can be achieved by improving construction of turbine or use of low cost materials without compromising efficiency and reliability of turbine. Operation and Maintenance (O\&M) costs can be minimized by decreasing number of downtime by designing more reliable turbines. Furthermore, COE can also be reduced by increasing the size of wind turbine that increases amount of energy generated annually. In the last three decades the trend proved that the growth of wind turbine technology has evolved. The turbine rotor diameters and rated power have 
enormously increased from $15 \mathrm{~m}$ to exceed $178 \mathrm{~m}$ rated at $50 \mathrm{~kW}$ to more than $10 \mathrm{MW}$ respectively by 2015 [8-11]. As the rotor diameter grows in size, structural weight and variation of aerodynamic loads along the span triggered the need to minimize fatigue loads at the major components such as rotor bearing, transmission shafts and generators. The purpose of present paper is therefore to overview the source loads that contribute to fatigue load and aerodynamic techniques employed to reduce the blade loading during operation of wind turbines.

\section{Fatigue load}

Fatigue loads on main components of wind turbine are caused by varying cyclic loads that act on different parts of the blades that eventually result to fatigue damage. According to Schubel et al [12] fatigue damage can occur when materials or structures are subjected to cyclic non continuous loads that exceed the fatigue limit of such materials. In wind turbine, fatigue damage is caused by resultant of cyclic (fatigue) loads acting on the turbine's structures which is equal to the number of rotations in the lifetime of the turbine, typically 20 years [13]. Fatigue damage in wind turbine can be escalated by enlargement and flexibility of structures, vibrations in its resonant mode, randomness in the load spectra due to the nature of the wind, continuous operation under different conditions, lower maintenance during life time [14]. After sometime, fatigue loads can cause tiny cracks on the structures due to inability to withstand excessive load. The loads acting on the blades are regarded as aerodynamic load, gravitation load, load due to inertia and mechanical control load [12, 13, 15-18]. Mechanical control loads can be controlled by the same techniques used for aerodynamic and gravitation loads since they have little impact on fatigue damage $[12,17]$. They depend on pitch control system and twist of the blades. Fig. 2 , shows three major loads that can cause fatigue failure on wind turbine structures and components.

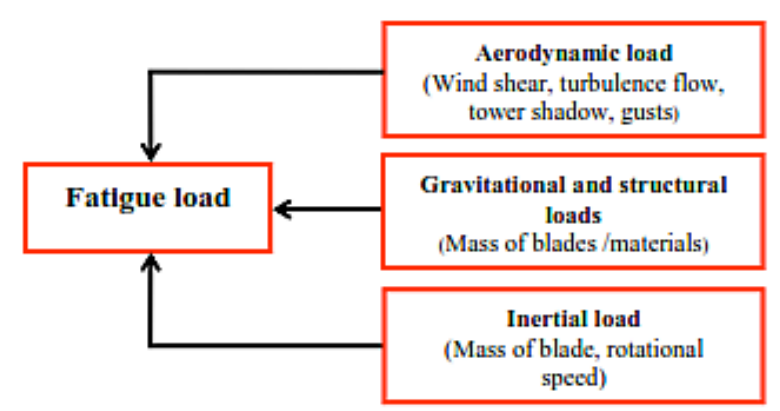

Fig. 2. Source of fatigue load on wind turbine

Inertial load is experienced when the turbine is subjected to emergency stop to safeguard the turbine from destruction by gusts. Mass and rotational speed of the rotor are major factors that influence the magnitude of inertial load. Centrifugal and gyroscopic loads cause an asymmetrical out of plane deflections of the blades while emergency braking induces edge-wise bending of the blade, thereby contributing to fatigue load.

Structural and gravitational loads are mass dependent loads. As the size of the blade increases, gravitation load significantly generates alternating tensile and pressure forces along the span of the blade and large alternating bending moments chord-wise and flap-wise axes per rotor revolution $[13,16]$. Gravitational load varies with azimuthal angle causing edgewise excitation and structural dynamics at the rotation frequency of the rotor that contribute to fatigue load.

Aerodynamics load is a resultant load caused by pressure exerted on surfaces of the blade's profile when the air blows over the blade. This load varies depending on the relative wind velocity, rotational speed of the rotor and angle of attack. The variation of aerodynamic load across different parts of the blade is shown in Eq. (2) as adopted from Johnson et al. [7]

$$
\begin{aligned}
& L=\int_{0}^{R} \frac{1}{2} C_{L} \rho c\left[V_{\text {wind }}^{2}+(2 \pi n r)^{2}\right] d r \\
& C_{L \min } \leq C_{L}=C_{L \alpha}\left(\alpha+\beta-\alpha_{0}\right) \leq C_{L \max }
\end{aligned}
$$

where; $\beta$ represent incidence angle of the blade, $\rho$ is air density, $\mathrm{n}$ denotes revolution per second, $c$ is chord of the blade, $\mathrm{R}$ is radius of rotor, $C_{L \min }, C_{L \alpha}, C_{L \max }$ are lift coefficient (minimum, corresponding to angle of attack and maximu) respectively, $\alpha_{0}$ is zero angle of attack and $\left\lfloor V_{\text {wind }}^{2}+(2 \pi n r)^{2}\right\rfloor$ represent squared relative wind speed.

Furthermore, periodic aerodynamic loads are developed on the blades due to fluctuation of wind flow, wind shear and gust which results to a complex aero-elastic interplay that produces vibrations and resonances [19]. The oscillating aerodynamic load can cause yaw and tilt misalignments because of high transient forces [17, 20]. Tawade et al [21] noted that a progressive damage on mechanical components or blades may occur if rotor blades are subjected to these periodic stresses for a long period. The work of Hansen et al [22] noted that a rotating blade passing through spatially varying wind field is excited at the frequency of passage which results to energy shifts to higher frequencies and causes more fatigue build-up than anticipated. Nevertheless, long blades are flexible and they are likely to experience edge-wise and flap-wise deflections especially in high varying wind speed. Staino and Basu and Shen et al $[18,23]$ have revealed that edge-wise mode vibrations have little or none aerodynamic dumping, while flapwise mode vibrations are aerodynamically dumped, thereby, edgewise can induce instabilities while the flapwise contribute to fatigue damage.

\section{Aerodynamic load control methods}

In past decades, wind turbines have tremendously evolved in terms of technology from a passively controlled phase to a sophisticated actively controlled phase where reliability and efficiency are highly dependent upon a well-designed control strategy $[24,25]$. The rotor blades are dynamically flexible under high risk of striking the tower during high wind speed due to high tip deflection. In such scenario, safety and optimal operation of turbines are far from being reached. High periodic and alternating aerodynamic loads due to wind shear and turbulence flow over the blades can cause catastrophic damage, if the load control systems in place are unable to dumb excessive transitional loads immediately. Abrupt or moderate decrease in service life of turbines, raise of operational and maintenance costs due to unplanned downfall times for repairs are attributes of fatigue 
damage. Massive losses can be accrued on returns to investment. However, to reduce losses several methods are proposed to improve load control in large wind turbine.

Johnson el al [25] comprehensively reviewed feasible techniques that are applicable to wind turbines where some are borrowed from helicopter and aircraft field. Fig.3, shows types of load control techniques that are mainly categorized either as passive or active.

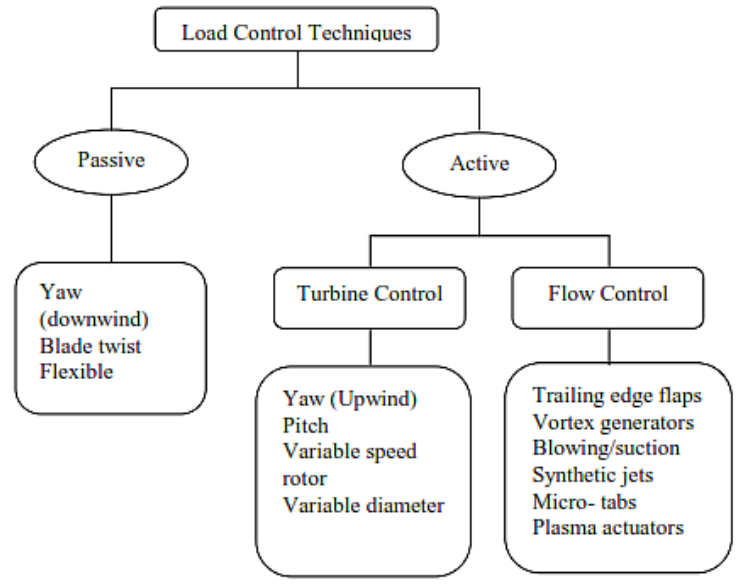

Fig. 3. Types of load control techniques [25]

According to Barlas et al [26] passive load control techniques can be realized when variations in wind speed are offset passively by adapting aero-elastic response of the rotor blades, but active load control methods are achieved when the aerodynamic properties of the blades are changed by either adjusting angle of attack or camber configuration of the blades. Passive load control methods are inherent on the blades and consume no power unlike active control methods which require power to perform. However, passive methods are of less help when wind speed is above rated power or under strong turbulence flow. This paper reviews turbine control methods and flow control methods.

\subsection{Turbine pitch control}

Different types of turbine pitch control systems are broadly employed in modern wind turbines to regulate power generation. They include; collective pitch control (CPC), individual pitch control (IPC) and cyclic pitch control (CP). Collective pitch control system rotates all the blades about their axes simultaneously. In addition, the CPC system makes rotor blades lighter during lower load spectrum that enable usage of lighter gear boxes because of shaved torque peaks [27]. On the other hand, Individual pitch control (IPC) is individually adjusted to control periodic loads. Cyclic pitch control (CP) system does change the pitch angle of blades depending on blades position about their hub. Individual pitch control and cyclic pitch control are considered as advanced pitch control mechanisms with better performance than collective pitch control. According to Larsen et al [28] individual pitch control has capability to reduce fatigue load by $26 \%$ and $6 \%$ for extreme load, likewise cyclic pitch control can reduce fatigue and extreme loads by $21 \%$ and $3 \%$ respectively. However, as rotor increases in diameter, the blades become more flexible and heavier. These systems reach their capability limits to control excessive (extreme and fatigue) loads on the blades during high varying wind speed. The actuation rate of actuators are limited by inertia load caused by huge mass, thereby, making the system unreliable [17].
From literature [14, 20, 25, 29-31], some limitations of pitch control systems are identified in large wind turbines. These include; (1) rotating the entire blade is not ideal due to induced non-uniform aerodynamic loads across the blade span; (2) the limited time response requirements to counter winds perturbations. These control systems are unable to respond rapidly because the speed of actuators is limited by structural weight of the blades; (3) excessive usage of actuator leads to wear of pitch bearing and actuator resulting to unscheduled replacement and maintenance. The wear of bearings and actuators is likely occur due to relatively high pitch angles and rates demanded to counteract wind fluctuations; (4) large pitch motor size is required that leads to high power demand for operation of the system.

\subsection{Flow control methods}

Johnson et al., Barlas and Kuik, Pechlivanoglou et al. [25, 26, 32] reviewed active flow control method comprehensively. According to Johnson et al [25] all active flow control devices involve four grouping layers as summarized in Table 1.

Layer I: Design features; geometric $(\mathrm{G})$, fluidic $(\mathrm{F})$ or plasma (P),

Layer II: Location of devices: leading edge (LE), mid chord (MC) or trailing edge (TE),

Layer III: Performance: Increase lift (IL), decrease lift (DL) or delay stall (DS),

Layer IV: Operation conditions: Steady flow (S) or Unsteady flow (U)

Table 1 Categorization and grouping of locally distributed aerodynamic devices on rotor blades [25].

Aerodynamic devices LayerI LayerII LayerIII LayerIV $\mathrm{G} / \mathrm{F} / \mathrm{PLE} / \mathrm{TE} / \mathrm{IL} / \mathrm{DL} / \mathrm{S} / \mathrm{U}$ $\mathrm{MC} \quad \mathrm{DS}$

\begin{tabular}{lcccc}
\hline $\begin{array}{l}\text { Deformable/morphing } \\
\text { trailing edge flap }\end{array}$ & $\mathrm{G}$ & $\mathrm{TE}$ & $\mathrm{IL} / \mathrm{DL}$ & $\mathrm{S} / \mathrm{U}$ \\
$\begin{array}{l}\text { Traditional trailing } \\
\text { edge flaps }\end{array}$ & $\mathrm{G}$ & $\mathrm{TE}$ & $\mathrm{IL} / \mathrm{DL}$ & $\mathrm{S} / \mathrm{U}$ \\
$\begin{array}{l}\text { Microtabs trailing } \\
\text { Miniature }\end{array}$ & $\mathrm{G}$ & $\mathrm{TE}$ & $\mathrm{IL} / \mathrm{DL}$ & $\mathrm{S} / \mathrm{U}$ \\
edge effectors & $\mathrm{G}$ & $\mathrm{TE}$ & $\mathrm{IL} / \mathrm{DL}$ & $\mathrm{S} / \mathrm{U}$ \\
Microflaps & $\mathrm{G}$ & $\mathrm{TE}$ & $\mathrm{IL} / \mathrm{DL}$ & $\mathrm{S} / \mathrm{U}$ \\
Active stall strips & & & $\mathrm{DL}$ & $\mathrm{S}$ \\
Vortex generators & $\mathrm{G}$ & $\mathrm{LE}$ & $\mathrm{DS}$ & $\mathrm{S}$ \\
Blowing and suction & $\mathrm{F}$ & $\mathrm{LE} / \mathrm{TE}$ & $\mathrm{DS}$ & $\mathrm{S} / \mathrm{U}$ \\
Circulation control & $\mathrm{F}$ & $\mathrm{TE}$ & $\mathrm{IL} / \mathrm{DL}$ & $\mathrm{S}$ \\
Plasma Actuator & $\mathrm{P}$ & $\mathrm{LE}$ & $\mathrm{DS}$ & $\mathrm{S}$ \\
Vortex generators jet & $\mathrm{F}$ & $\mathrm{LE}$ & $\mathrm{DS}$ & $\mathrm{S} / \mathrm{U}$ \\
High frequency micro & $\mathrm{G}$ & $\mathrm{LE}$ & $\mathrm{DS}$ & $\mathrm{U}$ \\
vortex generators & & $\mathrm{LE}$ & $\mathrm{DS}$ & $\mathrm{U}$ \\
Synthetic jets & $\mathrm{G} / \mathrm{F}$ & $\mathrm{LE}$ & $\mathrm{DS}$ & $\mathrm{U}$ \\
Active flexible wall & $\mathrm{G}$ & $\mathrm{H}$ & $\mathrm{IL}$ & $\mathrm{S} / \mathrm{U}$ \\
Shape change airfoil & $\mathrm{G}$ & $\mathrm{MC}$ & $\mathrm{L}$
\end{tabular}

Key: G -geometric , F - fluidic, P-plasma, LE- leading edge, MC- mid chord, TE - trailing edge, IL - increase lift, DL- decrease lift, DS -delay stall, S- steady flow, Uunsteady flow.

Barlas and Kuik [26] compared the capabilities of the active flow devices in controlling aerodynamic loads on the blades. Their work was based on empirical analysis as illustrated in Fig.4. 


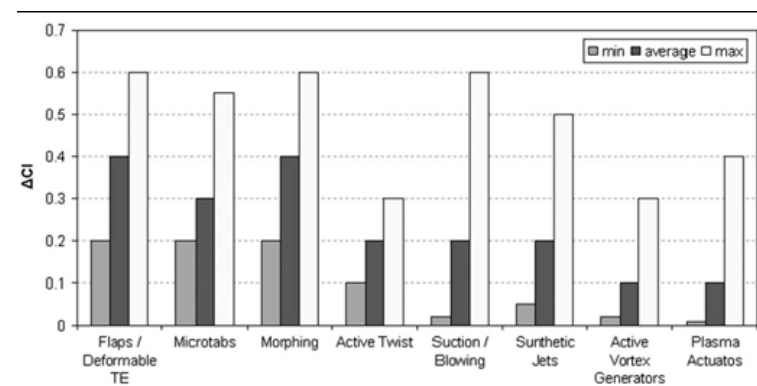

Fig 4. Comparison of capabilities of active flow control devices for load reduction [26].

Pechlivanoglou et al. [32] extensively performed optimization of wind turbine rotor both experimentally and numerically. Authors extended their investigation on the following active flow devices; Flexible trailing edge flap, Gurney flap and micro tabs, Stall rib and flexible leading edge flap. Use of such aforementioned control devices moved modern wind technology to Smart rotor technology.

\section{Smart rotor concept}

Smart control concept involves technology that embeds aerodynamic devices, smart materials, sensors, actuators and controllers to change aerodynamic flow over the blade profile. The system action depends on direction and magnitude of relative wind over the rotor at a given time. A smart rotor can, therefore, be defined as a structural system that comprises of local distributed aerodynamic devices connected with intelligence features that are built on the rotor blades with spread actuators and sensors [26]. Sensors are linked with one or two microprocessors for analyzing responses from the sensors, then uses integrated control theory to command the actuators for localized strain /displacement that alter the system response [33]. The smart rotor control concept was revived in Europe under programme entitled Upwind EU-framework programme [12, 26]. A typical smart rotor is shown in Fig.5, where line S symbolizes distributed sensors, line D signifies locally distributed aerodynamic devices and hidden lines with arrows show directions of information in system components, $\mathrm{BC}$ is blade control while $\mathrm{MC}$ is master control.

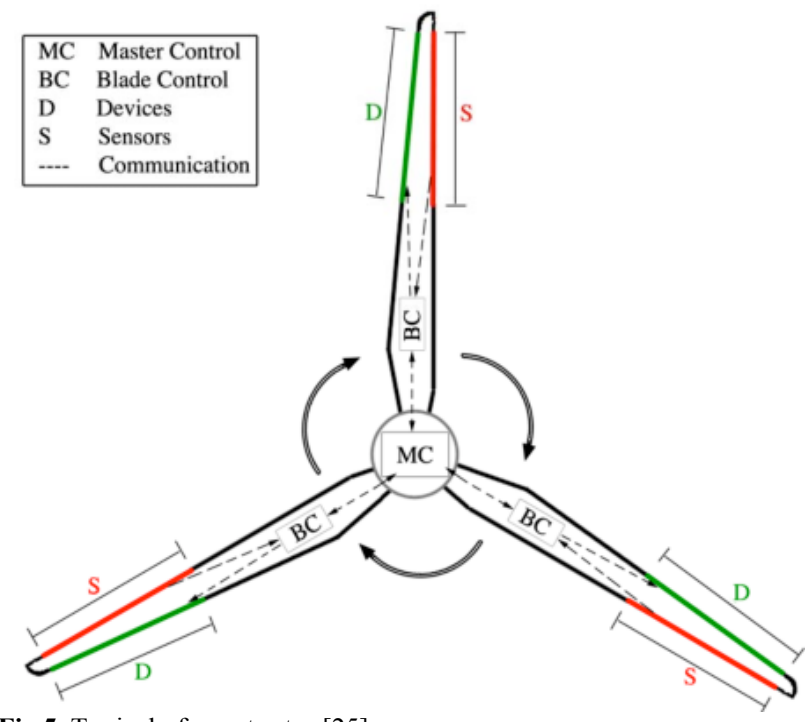

Fig.5. Typical of smart rotor [25]
The sensors receive signal from inflow wind and transmit loads as input to the blade controllers. From blade controllers the signal is transmitted to master controller at the hub which in turn reverses the signal to the aerodynamic devices through blade controllers. In doing so, aerodynamic devices automatically deflect in a respective direction depending on inflow wind. Several investigations on smart rotor have been undertaken in various universities and laboratories such as DTU RIS $\varnothing$, TU Delft, University of Stuttgart and Sandia National Laboratories [34]. These researches use different methodology approaches, however, the main objective is to effectively reduce root bending moments and oscillating loads along the blades. Literature has revealed that the use of aerodynamic surfaces can actively mitigate excessive (extreme and fatigue) loads, suppress flap-wise vibrations caused by fluctuating inflow, increase the frequency bandwidth and overcome stochastic conditions unlike individual pitch control system $[14,31]$.

\section{Aerodynamic devices}

Here, aerodynamic devices subject for discussion are identified as; micro-tab, rigid trailing edge flap, morphing flap and deformable trailing edge. Generally, they are employed either to increase or decrease the aerodynamic loads or to delay stall. They increase aerodynamic force on span by deflecting them on pressure side and decrease aerodynamic force by deflecting them on suction side. If aerodynamic force along the blade span (especially near the tip of the blade) is reduced, this can be translated to reduction of bending moment at the root of the blade. The effects of fatigue loads on the blade structures and essential components are minimized. Then lifespan of wind turbine can be prolonged by delaying fatigue damage.

A brief history of employment of trailing edge flaps on wind turbine can be found in literature [35-37]. This concept of applying aerodynamic devices has then been revived with more advanced technology in place and it is taking shape in current wind turbine research field. Various journal articles have been published on active flow control using different aerodynamic devices. For example; micro-tabs [38-43], Rigid trailing edge flap [44, 45], deformable trailing edge flap (DTEF) [14, 24, 44-52] and morphing trailing edge [44, 45, 53-58]. Upwind Offshore NREL 5MW wind turbine [59] has been used extensively to investigate reduction of load on multi megawatts turbine $[14,45,49-52,60,61]$.

\subsection{Micro-tab}

A micro-tab can be described as a small extractable and retractable surface element with a height of boundary layer thickness $(1-2 \%$ Chord) that can move in translational motion approximately normal to the blade's profile. Microtabs are deployed to enhance aerodynamic performance. From literature, micro-tabs are effective when located at $95 \%$ of chord on pressure surface and about $90 \%$ chord on suction surface $[38,43]$. When they are actively extracted from blades the flow at trailing edge violates Joukowsky theory on steady airflow as shown in Fig.6, (a). Fig.6, (b) shows direction of change in lift forces depending on the side of extraction.

Bach et al [38] investigated transitional effects of applying active micro-tab at mid and outboard region of the 
blade and found that lift transitional response delay is due to presence of downstream convent vortex around the aerofoil's surfaces and probably earth's boundary layer or yaw misalignment per revolution.
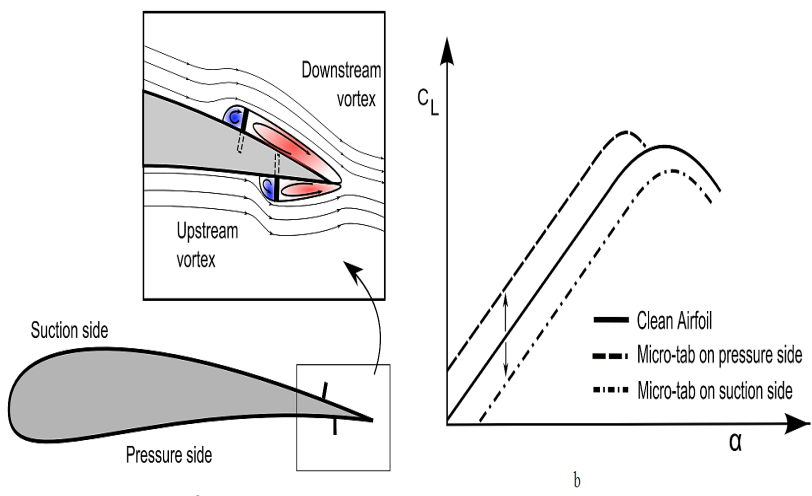

Fig. 6. (a) Micro-tabs (b) Lift coefficient versa angle of attack [38].

The results obtained by Zaras et al [43] concurs with Yen-Nakafuji and Baker et al $[39,42]$. Both results suggest micro-tab as a potential aerodynamic device for load reduction despite research being done for a small wind turbine. Direct comparison with large wind turbine can bring discrepancies although there is hardly known literature about effectiveness of micro-tabs on multi-megawatt wind turbines to the best of our knowledge.

\subsection{Trailing edge flaps}

Trailing edge flap is a small lifting surface placed at rear portion of the chord with capability to deflect either upward or downward to change the magnitude of aerodynamic load. The trailing edge flaps (TEF) are designed in various configurations and sizes. They include; plain rigid flap, morphing trailing flap and deformable trailing edge flap (DTEF). In common, trailing edge flaps have ability to control locally distributed vibrations and inflow around the rotor blades [46]. Pettas et al. [62] used Denmark Technical University (DTU) $10 \mathrm{MW}$ to investigate the impact of an individual trailing edge flap on wind power generation. Their findings proved that DTU $10 \mathrm{MW}$ rotor blades can be increased by $5 \%$ to increase the annual power production by $3.6 \%$ without altering fatigue load originally experienced by turbine before modification. Smit et al. [61] advocated that the secondary purpose of trailing edge flap under rated power wind speed is to optimize power generation, since the fatigue load is insignificant and approximately account for $2 \%$.

\subsubsection{Morphing trailing flap}

Implementation of morphing trailing edge flap on wind turbine blades is an idea that originated from the design of morphing aircraft wings and helicopter blades [26, 55-58]. The blade design is made of two portions as shown in Fig.7; detachable flexible rear part and fixed fore part. The benefits brought in by morphing flaps are; there is no discontinuities, hinge line and air gap created when the rear part is deflected unlike traditional rigid flaps [45]. Furthermore, morphing flap has better aerodynamic efficiency/performance $\left(\eta_{a e r o}=C_{l i f t} / C_{d r a g}\right)$ in comparison with a rigid plain flap.

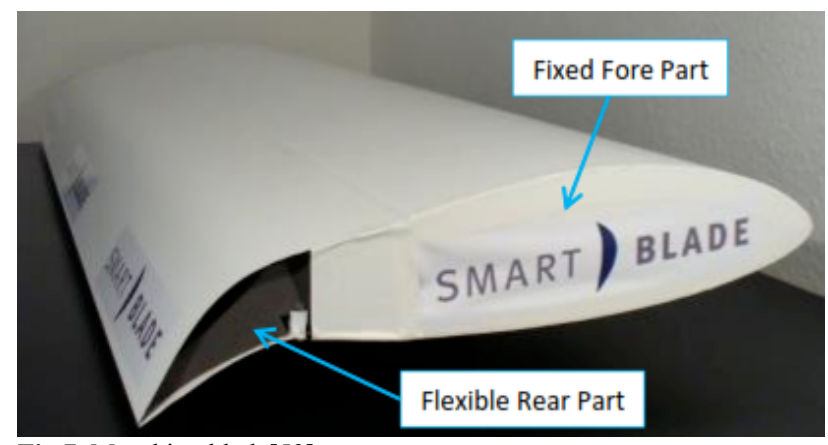

Fig.7. Morphing blade[53]

Several researches about morphing trailing flap have been conducted numerically and experimentally [44, 45, 6367]. Researchers identify morphing flap as a potential element for load reduction in up-scaling wind turbines. However, Daynes and Weaver [54] revealed that actuators work against aerodynamic load and stiffness of the structure causing no free movement of the flap. This may results to inefficiency of flap to act promptly on high wind speed. In addition, the space required for installation of actuator to control flap near the tip edge is limited.

\subsubsection{Deformable trailing edge}

Deformable trailing edge flap (DTEF) provides continuity aerofoil profile unlike rigid and morphing trailing edge flaps. Currently, deployment of DTEF in wind turbines is growing popular among the researchers over conventional trailing edge flap. Rotor blade integrated with DTEF can enjoy the following benefits; less aero-acoustic noise, minimal drag, increased aerodynamic performance, compliant structures and protection of internal components from erosive and corrosion environment. Henriksen et al [68] investigated the effect of DTEF in conjunction with turbine pitch control system. The researchers concluded that employment of DTEF would increase reduction of damage equivalent loads (DEL) from $18 \%$ to around $30 \%$. The flap actuator relieves turbine's pitch control from loading by $75 \%$. This leads to a reduction of maintenance and operation schedule times as the wear of pitch actuator is reduced.

Comparison of individual pitch control and smart rotor control embedded with DTEF can be found in [14, 31, 69]. Lackner and Kuik [14] derived conclusions that; (i) Individual pitch control significantly reduces loads at low frequency while individual flaps show strong ability to reduce loads at high frequency. (ii) Individual flap control thrive to stabilize fluctuations of power output and minimize pitching usage rate unlike individual pitch control which increases pitching usage rate with slight rise in amount of power generated. Zhang et al [51] used an offshore NREL $5 \mathrm{MW}$ upwind wind turbine equipped with DTEF to investigate load reduction due to extreme coherent gust with direction change. Further, Zhang et al [50] evaluated the effects of locating and sizing of deformable trailing edge flap (DTEF) in regard to fatigue load reduction. Their study involved variation of flap location placement, span-wise size, chord-wise size and deflection angle of the DTEF at rated power wind speed region II and cut out rated power wind speed region III. The reduction of fatigue load was improved as the placement of the DTEF approaches the tip except in region II when there was an increase in span-wise length, chord-wise and deflection angle of DTEF. Numerical results show positive reduction in fatigue load on both 
blades and drive chain components ranging between $15 \%$ $33 \%$ and $42.1 \%-32.3 \%$ respectively.

Smit et al [61] also investigated the effect of sizing, placement and number of trailing edge flap (TEF) with a fixed chord of $10 \% \mathrm{C}$ using NREL 5MW wind turbines as reference turbine. Researchers concluded that employment of TEF under rated power wind speed can be used to increase energy capture rather than prevention of fatigue damage which account for about $2 \%$ during service life of a wind turbine. Therefore, it is not economical to apply aerodynamic devices under rated power wind speed and can be neglected. The power extraction increases as location of the TEF (a unit metre long) is changed towards the tip of the blade. A large trailing edge flap tends to generate more power but its effectiveness deteriorates as the span length is increased. Authors recommended location of TEF to start from $95 \% \mathrm{R}$ and be extended towards the root of the blade. It was also noted that a single flap of one metre length yield better performance compared with multi-segmented flaps.

To substantiate the concept of employing DTEF on multi megawatt wind turbine, Zhang et al [52] investigated the influence of DTEF under the effect of wake. Wind turbines were arranged in column, row and arrays scenarios and evaluation was validated as a single wind turbine case. The results show significant reduction in standard deviation of the flapwise root moment (30\%), tipwise deflection $(20 \%)$ and damage equivalent load $(20 \%)$ in the region III at hub velocity of $20 \mathrm{~m} / \mathrm{s}$. From Zhang et al [50-52] works, DTEF is identified as a champion candidate for load reduction between rated power and cut-out power.

However, both control concepts have no influence on power production above rated power wind speed. Plumley et al [31] compared power requirement, the rate of actuator and acceleration as well as load reduction for both individual pitch control and smart control concept using collective pitch control as a baseline.

\subsubsection{Flexible trailing edge flap}

Barlas and Madsen [47] examined the influence of actuator on using controllable rubber trailing edge flaps (CRTEF) in turbulence scenario. Fischer et al [65] investigated industrial feasibility of using flexible trailing edge flap with control system integrated in a small wind turbine prototype $(250 \mathrm{~kW})$. Two flaps with different chords $20 \% \mathrm{C}$ and $30 \% \mathrm{C}$ were investigated respectively. Their research deduced that flap with a larger chord has higher control authority than smaller chord. There is also more space to integrate the mechanical linkages for actuation. The effects deflecting high flexible flaps on suction and pressure sides can be found in the work of Pechlivanoglou et al [53].

\section{Winglets}

Use of winglets is broadly applied in the field of nonrotating application to enhance aerodynamic performance by shedding off vortex at the tip of the wing [70]. The main idea of using winglets is to improve overall aerodynamic efficiency by reducing induced drag generated due to tip vortices flow. From literature [70-72], winglets can be used on wind turbine blades to increase power coefficient thus decrease costs of energy, reduce amount of vortex flow at the tip of the blades thus reduce induced drag, reduce overall diameter so that load can be minimized, reduce noise emitted by the blade. A winglet can, therefore, be defined as a load carrying device that reduces the spanwise flow, diffuses and moves the tip vortex away from the rotor plane decreasing the downwash and thereby reduces induced drag on the blade according to Johansen and Sorensen [71]. The major winglet geometric parameters are shown in Fig.8.

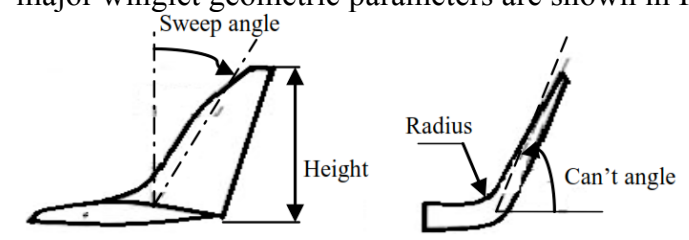

Fig. 8. Geometry parameters of winglet

Gupta and Amano [73] investigated the influence of adding winglet on wind turbine blades in terms of power generated. Two key geometric parameters (can't angle and winglet height) were varied and increase in power production was recorded ranging from $2 \%$ to $20 \%$. As a result, researchers concluded that power increases with increase in height of winglets. In addition, inclined winglets $\left(45^{\circ}\right)$ performed better than winglets fixed perpendicular $\left(90^{\circ}\right)$ to the surface of the blade. However, it is argued that trade-off between structural weight and aerodynamic performance are required to determine economic prospective of wind turbine. Gaunaa, Johansen and Sorensen [70, 71] found that winglets can increase annual power generation by $1 \%$ to $2 \%$ with downwind winglet being more effective than upwind winglet despite the risk of striking the tower. Inclusion of sweep and cant angles parameters was suggested to improve performance of winglet. Elfarra et al. [74] varied can't and twist angle of winglets in determination of maximum torque for maximum power generation. NREL VI wind turbine could increase annual power production by around $9 \%$ when optimized tilted tips of $1.5 \% \mathrm{R}$ height are considered.

\section{Discussion and conclusion}

Design of large wind turbines involves balancing of design requirements such as durability, structural and aerodynamic performance in order to achieve a more reliable design. From the literature reviewed it is evident that by increasing the rotor diameter, so do weight and flexibility of the blades. The fatigue load that gets accumulated at hub due to severe operating conditions such as high wind shear, turbulence and tower shadow became critical. This load can lead to several downfall times during unplanned maintenance and replacement of damaged components. What follow is; unscheduled maintenances reduces income on invested capital and trigger prices of power to go up. If the cost of energy is to be reduced by increasing the rotor diameter, then there is need to find alternative and reliable ways of controlling excessive load during high varying wind.

Gravitation and inertial loads are taken as major loading on the blade that has less influence on alteration of fatigue load. Wind turbines are designed and projected to operate for not less than 20years, however due to their operating conditions that involve frequent periodic turbulence cause them to fail earlier than their design life time. It is therefore noted that high periodic and alternating aerodynamic loads on the blades are inevitable, so do fatigue loads. In attempt to keep structural and durability properties, blades are manufactured from materials which have high fatigue limits and light in weight, however it is not enough to withstand loading on the blades. The longer the blade, the more the bending stress experienced at the root of the rotor hence more fatigue loads [21]. This leads to demand for a more 
reliable method to reinforce or substitute traditional methods which have been extensively used in most of the modern wind turbines.

Literature reviewed suggests that use of aerodynamic devices can significantly reduce periodic loads on the large wind turbine blades as well as increase power generation during the low wind speed. In search for the load reduction strategies, researchers proposed for utilization of aerodynamic devices such as micro-tab, trailing edge flaps, morphing flaps and deformable trailing edge. Micro-tabs are potential small surfaces that can actively reduce exceeding load on the blade during high wind, however there is hardly know research that introduce use of micro-tabs on large horizontal wind turbine. Rigid trailing flap are equally serve as deformable and morphing trailing flaps, but due to discontinuity created during movement of the flap it generates more noise and cause drag increment. Morphing and deformable trailing edges are preferable devices for they do not create gaps during their application. These aerodynamic devices are able to change the flow profile and delay flow separation along the chord.
Aerodynamic load on the blade is altered when the flaps are deflected either to increase or decrease the load. The trailing flaps also do suppress vibrations, minimize emission of aero-acoustic noise and minimize tip deflections. An advantage of suppressing blade tip deflection is to reduce possibility of blades to strike the tower. Deformable and trailing edge flaps show the highest capability of controlling periodic aerodynamic loads and reduce root bending moment with about $30 \%$ of original load. The concept that makes use of aerodynamic devices is known as smart rotor. Table 2 summarized few researches done utilizing offshore NREL 5MW baseline wind turbine embedded with trailing edge flaps as a tool to reduce the fatigue load at hub. Sizes and locations of trailing edge flaps, maximum deflection angles, rate of deflection, simulation codes used and approximated amount of load reduction are shown in the Table 2. It is argued that by relating the amount of fatigue reduced, a small increase in rotor blade diameter can be implemented without changing the original root bending moments. Therefore innovative design of smart rotor can boost increase in power production by increasing rotor diameter without overloading main components at hub.

Table2. Summary of referenced blade showing type, location and size of trailing edge flaps.

\begin{tabular}{|c|c|c|c|c|c|c|c|c|c|c|c|}
\hline & Referenced Wind & Rotor & Aerodynamic & & Aerodyna & amic device par & rameter & & & Simulation & \\
\hline & Turbine & $\begin{array}{l}\text { diameter } \\
\text { (m) }\end{array}$ & $\begin{array}{c}\text { device/airfoil } \\
\text { type }\end{array}$ & Chord & Length & location & $\begin{array}{c}\text { Max } \\
\text { deflect- } \\
\text { ion }\end{array}$ & \begin{tabular}{|c|}
$\begin{array}{c}\text { Deflec- } \\
\text { tion rate }\end{array}$ \\
\end{tabular} & reduction & code & Paper \\
\hline 1 & $\begin{array}{l}\text { NREL } \\
\text { Upwind/5MW } \\
\text { offshore }\end{array}$ & 126 & $\begin{array}{l}\text { Rigid plain } \\
\text { trailing flap }\end{array}$ & $10 \%$ & $16.2 \% \mathrm{R}$ & $77 \%-93.2 \%$ & $\pm 30^{\circ}$ & $60^{\circ} / \mathrm{s}$ & & & {$[31]$} \\
\hline 2 & $\begin{array}{l}\text { NREL } \\
\text { Upwind/5MW } \\
\text { offshore }\end{array}$ & 126 & $\begin{array}{l}\text { Deformable } \\
\text { trailing edge } \\
\text { flap }\end{array}$ & $10 \%$ & $20 \%$ & $70 \%-90 \%$ & $\pm 10^{\circ}$ & $40 \% \mathrm{~s}$ & $30 \%$ & GH bladed & {$[14,30]$} \\
\hline 3 & $\begin{array}{l}\text { NREL } \\
\text { Upwind/5MW } \\
\text { offshore }\end{array}$ & 126 & $\begin{array}{l}\text { Deformable } \\
\text { trailing edge } \\
\text { flap }\end{array}$ & $10 \%$ & $20 \%$ & $77.6 \%-97.6 \%$ & $\pm 10^{\circ}$ & $\geq 50^{\circ} / \mathrm{s}$ & $16 \%$ & $\begin{array}{l}\text { HAWC2 } \\
{[75]}\end{array}$ & {$[68]$} \\
\hline 4 & $\begin{array}{l}\text { NREL } \\
\text { Upwind/5MW } \\
\text { offshore }\end{array}$ & 126 & $\begin{array}{l}\text { Deformable } \\
\text { trailing edge } \\
\text { flap }\end{array}$ & $10 \%$ & $\begin{array}{l}10 \% \\
20 \%\end{array}$ & & $\pm 8^{\circ}$ & & $25 \%$ & HAWC2 & {$[62]$} \\
\hline 5 & $\begin{array}{l}\text { 1.5MW Wind PACT } \\
\text { DTU } 10 \mathrm{MW}\end{array}$ & $\begin{array}{l}65.9 \\
178.3 / 187.2\end{array}$ & $\begin{array}{l}\text { Morphing } \\
\text { trailing edge } \\
\text { 2FFA-W3-241 }\end{array}$ & $\begin{array}{l}20 \% \\
10 \%\end{array}$ & $\begin{array}{l}30 \% \\
25 \% \mathrm{R} \\
30 \%=29.7\end{array}$ & $\begin{array}{l}\text { outboard } \\
\text { Outboard }\end{array}$ & $\begin{array}{l} \pm 10^{\circ} \\
\pm 15^{\circ}\end{array}$ & $100 \% \mathrm{~s}$ & $\begin{array}{l}37 \% \\
30 \%\end{array}$ & \begin{tabular}{|l|} 
FAST/ \\
Aerodyn \\
Hawc / cfd
\end{tabular} & {$[44,45]$} \\
\hline
\end{tabular}

\section{Acknowledgements}

This research has been supported by Mobility to Enhance Training of Engineering Graduates in Africa (METEGA) one of Intra-ACP mobility schemes supported projects.
Access article distributed under the terms of the Creative Commons Attribution License

\section{References}

1. A. Evans, V. Strezov, and T. J. Evans, "Assessment of sustainability indicators for renewable energy technologies," Renewable and sustainable energy reviews, vol. 13, pp. 10821088, 2009.

2. J. Nicholls, R. Mawhood, R. Gross, and R. Castillo Castillo, "Evaluating Renewable Energy Policy: A Review of Criteria and Indicators for Assessment," 2014.

3. A. A. Bazmi and G. Zahedi, "Sustainable energy systems: Role of optimization modeling techniques in power generation and supply-A review," Renewable and Sustainable Energy Reviews, vol. 15, pp. 3480-3500, 2011.

4. D. Y. Leung and Y. Yang, "Wind energy development and its environmental impact: a review," Renewable and Sustainable Energy Reviews, vol. 16, pp. 1031-1039, 2012.

5. A. Zahedi, "Current status and future prospects of the wind energy," in IPEC, 2012 Conference on Power \& Energy, 2012, pp. 54-58.
6. J. L. Sawin, F. Sverrisson, W. Rickerson, C. Lins, L. E. Williamson, R. Adib, et al., "Renewables 2015 global status report-Annual Reporting on Renewables: Ten years of excellence," 2015.

7. S. J. Johnson, J. P. Baker, C. Van Dam, and D. Berg, "An overview of active load control techniques for wind turbines with an emphasis on microtabs," Wind Energy, vol. 13, pp. 239-253, 2010.

8. T. Ackermann and L. Söder, "Wind energy technology and current status: a review," Renewable and sustainable energy reviews, vol. 4, pp. 315-374, 2000.

9. G. W. c. Energy, "Global Wind Energy Outlook | 2014," 2014.

10. M. G. Molina and J. G. Alvarez, Technical and regulatory exigencies for grid connection of wind generation: INTECH Open Access Publisher, 2011. 
11. X. Sun, D. Huang, and G. Wu, "The current state of offshore wind energy technology development," Energy, vol. 41, pp. 298-312, 2012.

12. P. J. Schubel and R. J. Crossley, "Wind turbine blade design," Energies, vol. 5, pp. 3425-3449, 2012.

13. T. Burton, D. Sharpe, N. Jenkins, and E. Bossanyi, Wind energy handbook: John Wiley \& Sons, 2001.

14. M. A. Lackner and G. van Kuik, "A comparison of smart rotor control approaches using trailing edge flaps and individual pitch control," Wind Energy, vol. 13, pp. 117-134, 2010.

15. G. Failla and F. Arena, "New perspectives in offshore wind energy," Phil. Trans. R. Soc. A, vol. 373, p. 20140228, 2015.

16. E. Hau, "Wind turbines: fundamentals, technologies, application, economics," Springer: Berlin, Germany, 2006.

17. J. F. Manwell, J. G. McGowan, and A. L. Rogers, Wind energy explained: theory, design and application: John Wiley \& Sons, 2010.

18. A. Staino and B. Basu, "Emerging trends in vibration control of wind turbines: a focus on a dual control strategy," Philosophical Transactions of the Royal Society of London A: Mathematical, Physical and Engineering Sciences, vol. 373, p. 20140069, 2015.

19. E. Hau and H. Von Renouard, The wind resource: Springer, 2006.

20. T. Barlas and G. Van Kuik, "State of the art and prospectives of smart rotor control for wind turbines," in Journal of Physics: Conference Series, 2007, p. 012080.

21. S. V. Tawade, S. B. Todkar, and A. S. Hade, "Fatigue life optimization of wind turbine blade," International Journal of Research in Engineering and Technology, 2014

22. A. Hansen and C. Butterfield, "Aerodynamics of horizontal-axis wind turbines," Annual Review of Fluid Mechanics, vol. 25, pp. $115-149,1993$

23. X. Shen, X. Zhu, and Z. Du, "Wind turbine aerodynamics and loads control in wind shear flow," Energy, vol. 36, pp. 1424 1434, 2011.

24. D. G. Wilson, D. E. Berg, M. F. Barone, J. C. Berg, B. R. Resor, and D. W. LOBITZ, "Active Aerodynamic Blade Control Design for Load Reduction on Large Wind Turbines to Increase Energy Capture," Sandia National Laboratories (SNL-NM) Albuquerque, NM (United States)2009.

25. S. J. Johnson and D. E. Berg, "Active load control techniques for wind turbines," 2008

26. T. K. Barlas and G. Van Kuik, "Review of state of the art in smart rotor control research for wind turbines," Progress in Aerospace Sciences, vol. 46, pp. 1-27, 2010.

27. J. Van Wingerden, A. Hulskamp, T. Barlas, B. Marrant, G. Van Kuik, D. Molenaar, et al., "On the proof of concept of a'smart'wind turbine rotor blade for load alleviation," Wind Energy, vol. 11, p. 265, 2008.

28. T. J. Larsen, H. A. Madsen, and K. Thomsen, "Active load reduction using individual pitch, based on local blade flow measurements," Wind Energy, vol. 8, pp. 67-80, 2005.

29. Z. Chen and K. Stol, "An assessment of the effectiveness of individual pitch control on upscaled wind turbines," in Journal of Physics: Conference Series, 2014, p. 012045.

30. W. Yu, M. M. Zhang, and J. Z. Xu, "Effect of smart rotor control using a deformable trailing edge flap on load reduction under normal and extreme turbulence," Energies, vol. 5, pp. 3608-3626, 2012.

31. C. Plumley, W. Leithead, P. Jamieson, E. Bossanyi, and M Graham, "Comparison of individual pitch and smart rotor control strategies for load reduction," in Journal of Physics: Conference Series, 2014, p. 012054.

32. S. Daynes and P. M. Weaver, "A shape adaptive airfoil for a wind turbine blade," in SPIE Smart Structures and Materials+ Nondestructive Evaluation and Health Monitoring, 2011, pp. 79790H-79790H-11.

33. I. Chopra, "Review of state of art of smart structures and integrated systems," AIAA journal, vol. 40, pp. 2145-2187, 2002.

34. L. Bernhammer, G. Van Kuik, and R. De Breuker, "How far is smart rotor research and what steps need to be taken to build a full-scale prototype?," in Journal of Physics: Conference Series, 2014, p. 012008

35. P. G. Migliore, L. Miller, and G. Quandt, "Wind turbine trailing edge aerodynamic brakes," National Renewable Energy Lab., Golden, CO (United States) 1995

36. L. S. Miller, "Experimental investigation of aerodynamic devices for wind turbine rotational speed control. Phase 1," National Renewable Energy Lab., Golden, CO (United States); Wichita State Univ., KS (United States) 1995.
37. L. S. Miller, S. Huang, and G. Quandt, "Atmospheric tests of trailing-edge aerodynamic devices," National Renewable Energy Lab., Golden, CO (United States) 1998 .

38. A. Bach, D. Holst, C. Nayeri, and C. Paschereit, "Transitional effects of active micro-tabs for wind turbine load control," in ASME Turbo Expo 2013: Turbine Technical Conference and Exposition, 2013, pp. V008T44A010-V008T44A010.

39. J. Baker, K. Standish, and C. Van Dam, "Two-dimensional wind tunnel and computational investigation of a microtab modified S809 airfoil," AIAA Paper, vol. 1186, 2005.

40. T. Macquart and A. Maheri, "Integrated aeroelastic and control analysis of wind turbine blades equipped with microtabs," Renewable Energy, vol. 75, pp. 102-114, 2015.

41. T. Macquart, A. Maheri, and K. Busawon, "Microtab dynamic modelling for wind turbine blade load rejection," Renewable Energy, vol. 64, pp. 144-152, 2014.

42. D. Y. Nakafuji, C. Van Dam, R. Smith, and S. Collins, "Active load control for airfoils using microtabs," Journal of Solar Energy Engineering, vol. 123, pp. 282-289, 2001.

43. J. Zayas, C. van Dam, R. Chow, J. Baker, and E. Mayda, "Active aerodynamic load control for wind turbine blades," in European Wind Energy Conference, 2006.

44. D. G. Wilson, D. E. Berg, M. F. Barone, J. C. Berg, B. R. Resor, and D. W. Lobitz, "Active aerodynamic blade control design for load reduction on large wind turbines," in European Wind Energy Conference, Marseille, France, 2009, pp. 643-678.

45. D. E. Berg, D. G. Wilson, B. R. Resor, M. F. Barone, J. C. Berg, S. Kota, et al., "Active aerodynamic blade load control impacts on utility-scale wind turbines," in Proc. of WindPower Conf. \& Exhib, 2009.

46. T. Barlas, G. van der Veen, and G. van Kuik, "Model predictive control for wind turbines with distributed active flaps: incorporating inflow signals and actuator constraints," Wind Energy, vol. 15, pp. 757-771, 2012.

47. T. K. Barlas and H. Aagaard Madsen, "Influence of actuator dynamics on the load reduction potential of wind turbines with distributed controllable rubber trailing edge flaps (CRTEF)," in 22nd International Conference on Adaptive Structures and Technologies, 2011.

48. L. Bergami, "Adaptive Trailing Edge Flaps for Active Load Alleviation in a Smart," Energy, vol. 6, pp. 119-128, 2003.

49. M. A. Lackner and G. A. van Kuik, "The performance of wind turbine smart rotor control approaches during extreme loads," Journal of solar energy engineering, vol. 132, p. 011008, 2010.

50. M. Zhang, B. Tan, and J. Xu, "Parameter study of sizing and placement of deformable trailing edge flap on blade fatigue load reduction," Renewable Energy, vol. 77, pp. 217-226, 2015.

51. M. Zhang, B. Tan, and J. Xu, "Smart load control on large-scale wind turbine blades due to extreme coherent gust with direction change," Journal of Renewable and Sustainable Energy, vol. 7, p. $023110,2015$.

52. M. Zhang, B. Tan, and J. Xu, "Smart load control of the largescale offshore wind turbine blades subject to wake effect," Science Bulletin, vol. 60, pp. 1680-1687, 2015.

53. G. Pechlivanoglou, J. Wagner, C. Nayeri, and C. Paschereit, "Active aerodynamic control of wind turbine blades with high deflection flexible flaps," in Proceedings 48th AIAA Aerospace Sciences Meeting, 2010, pp. 4-7.

54. S. Daynes and P. Weaver, "Design and testing of a deformable wind turbine blade control surface," Smart Materials and Structures, vol. 21, p. 105019, 2012.

55. C. Thill, J. Etches, I. Bond, K. Potter, and P. Weaver, "Morphing skins," The Aeronautical Journal, vol. 112, pp. 117-139, 2008.

56. J. C. Gomez and E. Garcia, "Morphing unmanned aerial vehicles," Smart Materials and Structures, vol. 20, p. 103001, 2011.

57. S. Barbarino, O. Bilgen, R. M. Ajaj, M. I. Friswell, and D. J. Inman, "A review of morphing aircraft," Journal of Intelligent Material Systems and Structures, vol. 22, pp. 823-877, 2011.

58. F. Gandhi and P. Anusonti-Inthra, "Skin design studies for variable camber morphing airfoils," Smart Materials and Structures, vol. 17, p. 015025, 2008.

59. J. M. Jonkman, S. Butterfield, W. Musial, and G. Scott, "Definition of a 5-MW reference wind turbine for offshore system development," ed: National Renewable Energy Laboratory Golden, CO, USA, 2009.

60. D. G. Wilson, B. R. Resor, D. E. Berg, T. K. Barlas, and G. A. van Kuik, Active aerodynamic blade distributed flap control design procedure for load reduction on the UpWind $5 \mathrm{MW}$ wind 
turbine: American Institute of Aeronautics and Astronautics (AIAA), 2010

61. J. Smit, L. O. Bernhammer, S. T. Navalkar, L. Bergami, and M. Gaunaa, "Sizing and control of trailing edge flaps on a smart rotor for maximum power generation in low fatigue wind regimes," Wind Energy, 2015.

62. V. Pettas, T. Barlas, D. Gertz, and H. A. Madsen, "Power performance optimization and loads alleviation with active flaps using individual flap control," in Journal of Physics: Conference Series, 2016, p. 012010.

63. D. E. Berg, D. G. Wilson, M. F. Barone, B. R. Resor, J. C. Berg, J. A. Paquette, et al., "The impact of active aerodynamic load control on fatigue and energy capture at low wind speed sites," in European Wind Energy Conference, Marseille, France, 2009, pp. 16-19.

64. S. Daynes and P. M. Weaver, "A morphing trailing edge device for a wind turbine," Journal of Intelligent Material Systems and Structures, p. 1045389X12438622, 2012.

65. J. Fischer, G. Weinzierl, J. Wagner, and G. Pechlivanoglou, "Development of a Flexible Trailing Edge Flap and System Integration Concept for Wind Turbine Blades," in Paper presented at the 11th German Wind Energy Conference DEWEK, 2012, pp. 7-8.

66. X. Lachenal, S. Daynes, and P. M. Weaver, "Review of morphing concepts and materials for wind turbine blade applications," Wind Energy, vol. 16, pp. 283-307, 2013.

67. H. A. Madsen, A. C. Garolera, and T. Schettler, "Towards an industrial manufactured morphing trailing edge flap system for wind turbines," in Proceedings of EWEC, 2014.
68. L. C. Henriksen, L. Bergami, and P. B. Andersen, "A model based control methodology combining blade pitch and adaptive trailing edge flaps in a common framework," EWEA Annual Event, Vienna, Austria, 2013.

69. L. Bergami, V. A. Riziotis, and M. Gaunaa, "Aerodynamic response of an airfoil section undergoing pitch motion and trailing edge flap deflection: a comparison of simulation methods," Wind Energy, vol. 18, pp. 1273-1290, 2015.

70. M. Gaunaa and J. Johansen, "Determination of the maximum aerodynamic efficiency of wind turbine rotors with winglets," in Journal of Physics: Conference Series, 2007, p. 012006.

71. J. Johansen and N. N. Sørensen, "Numerical analysis of winglets on wind turbine blades using CFD," in European Wind Energy Congress, 2007.

72. B. Nanukuttan, J. Wang, and E. V. Anjuri, "Winglet for wind turbine rotor blade," ed: Google Patents, 2011.

73. A. Gupta and R. Amano, "CFD analysis of wind turbine blade with winglets," in ASME 2012 International Design Engineering Technical Conferences and Computers and Information in Engineering Conference, 2012, pp. 843-849.

74. M. A. Elfarra, N. Sezer-Uzol, and I. S. Akmandor, "NREL VI rotor blade: numerical investigation and winglet design and optimization using CFD," Wind Energy, vol. 17, pp. 605-626, 2014.

75. T. J. Larsen and A. M. Hansen, "How 2 HAWC2, the user's manual," 2007. 